\title{
Diffuse decreased gray matter in patients with idiopathic craniocervical dystonia: a voxel-based morphometry study
}

\author{
Camila C. Piccinin ${ }^{1 *}$, Luiza G. Piovesana ${ }^{2}$, Maria C. A. Santos ${ }^{1}$, Rachel P. Guimarães ${ }^{1}$, \\ Brunno M. De Campos ${ }^{1}$, Thiago J. R. Rezende ${ }^{1}$, Lidiane S. Campos ${ }^{2}$, Fabio R. Torres ${ }^{3}$, Augusto C. \\ Amato-Filho ${ }^{4}$, Marcondes C. França Jr. ${ }^{1,2}$, Iscia Lopes-Cendes ${ }^{3}$, Fernando Cendes ${ }^{1,2}$ and Anelyssa D'Abreu ${ }^{1,2}$
}

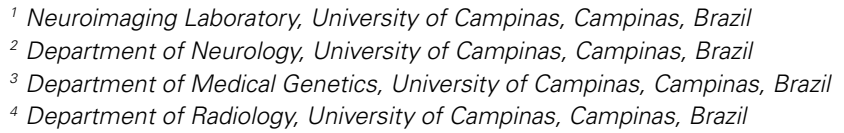

\section{Edited by:}

Antonio Pisani, Università degli Studi di Roma Tor Vergata, Italy

\section{Reviewed by:}

Paolo Calabresi, Santa Maria della Misericordia Hospital, Italy

Francesca Morgante, University of Messina, Italy

Giacomo Koch, Fondazione Santa Lucia IRCCS, Italy

Héctor Alberto González-Usigli, Instituto Mexicano del Seguro Social, Mexico

\section{*Correspondence:}

Camila C. Piccinin, Neuroimaging Laboratory, School of Medical

Sciences, University of Campinas, Cidade Universitária, Campinas, São Paulo 13083-887, Brazil

e-mail: camila.piccinin@gmail.com
Background: Recent studies have addressed the role of structures other than the basal ganglia in the pathophysiology of craniocervical dystonia (CCD). Neuroimaging studies have attempted to identify structural abnormalities in CCD but a clear pattern of alteration has not been established. We performed whole-brain evaluation using voxel-based morphometry (VBM) to identify patterns of gray matter (GM) changes in CCD.

Methods: We compared 27 patients with CCD matched in age and gender to 54 healthy controls. VBM was used to compare GM volumes. We created a two-sample $t$-test corrected for subjects' age, and we tested with a level of significance of $p<0.001$ and false discovery rate (FDR) correction $(p<0.05)$.

Results: Voxel-based morphometry demonstrated significant reductions of GM using $p<0.001$ in the cerebellar vermis IV $N$, bilaterally in the superior frontal gyrus, precuneus, anterior cingulate and paracingulate, insular cortex, lingual gyrus, and calcarine fissure; in the left hemisphere in the supplementary motor area, inferior frontal gyrus, inferior parietal gyrus, temporal pole, supramarginal gyrus, rolandic operculum, hippocampus, middle occipital gyrus, cerebellar lobules IVN , superior, and middle temporal gyri; in the right hemisphere, the middle cingulate and precentral gyrus. Our study did not report any significant result using the FDR correction. We also detected correlations between GM volume and age, disease duration, duration of botulinum toxin treatment, and the Marsden-Fahn dystonia scale scores.

Conclusion: We detected large clusters of GM changes chiefly in structures primarily involved in sensorimotor integration, motor planning, visuospatial function, and emotional processing.

Keywords: craniocervical dystonia, voxel-based morphometry, gray matter, cervical dystonia, segmental dystonia, neuroimaging

\section{INTRODUCTION}

Dystonia is a movement disorder characterized by involuntary sustained or intermittent muscle contractions causing abnormal, often repetitive, postures or movements (1). Blepharospasm (BSP), oromandibular, lingual, laryngeal, and cervical dystonia $(\mathrm{CD})$ are common forms of adult-onset dystonia. The term craniocervical dystonia (CCD) includes each of these conditions as well as their combinations. Although subjects with different manifestations of CCD probably have underlying differences in brain pathology, clinically there is a significant overlap. Several authors have studied $\mathrm{CCD}$ as a group suggesting the presence of common pathological mechanisms (2-7).

Classically considered, a manifestation of basal ganglia dysfunction, neuroimaging techniques have demonstrated structural, functional, and molecular brain abnormalities in areas such as the sensorimotor cortex and cerebellum $(2,7)$.
Voxel-based morphometry (VBM) allows for the evaluation of whole-brain structural changes by comparing two or more groups of MRI images (8). There have been eight published studies on morphometric gray matter (GM) abnormalities in patients with CD or BSP using VBM (9-16). The methodologies used were heterogeneous, and the results were variable without a consistent pattern of structural changes (Table 1). Moreover, we recently performed a cerebellar analysis in CCD using a specific template atlas for cerebellum, which found GM increase in the anterior cerebellar lobe and GM decrease in the posterior cerebellar lobe. Despite these interesting findings, in this technique, the infratentorial structures are isolated from the surrounding tissue (to avoid being biased by them), and therefore, the supratentorial areas were not studied (7). Thus, on the basis of previous conflicting results in the literature, our aim was to investigate morphological abnormalities in GM in CCD in order to better elucidate and 
Table 1 | Comparison of methodologies and results of previous VBM studies in craniocervical dystonias

\begin{tabular}{|c|c|c|c|c|c|c|c|c|c|c|}
\hline Ref. & MRI & SPM & FWHM & Mod & Dys & PTS & $\mathrm{HC}$ & $p$ value & Decreased GM & Increased GM \\
\hline $\begin{array}{l}\text { Draganski } \\
\text { et al. (9) }\end{array}$ & $1.5 \mathrm{~T}$ & SPM99 & $10 \mathrm{~mm}$ & No & CD & 10 & 10 & $\begin{array}{l}<0.05 \\
\text { correct }\end{array}$ & $\begin{array}{l}\text { R caudal SMA, R visual cortex, } R \\
\text { dIPFC }\end{array}$ & $\begin{array}{l}\text { R GPi, bilateral motor cortex, } \\
\text { cerebellar flocculus }\end{array}$ \\
\hline $\begin{array}{l}\text { Etgen } \\
\text { et al. (13) }\end{array}$ & $1.5 \mathrm{~T}$ & SPM2 & $12 \mathrm{~mm}$ & No & BSP & 16 & 16 & $\begin{array}{l}<0.001 \\
\text { uncorrected }\end{array}$ & L inferior parietal lobule & Bilateral putamen \\
\hline $\begin{array}{l}\text { Egger } \\
\text { et al. (10) }\end{array}$ & $1.5 \mathrm{~T}$ & SPM2 & $12 \mathrm{~mm}$ & No & $C D$ & 11 & 11 & $\begin{array}{l}<0.05 \\
\text { correct }\end{array}$ & & $\begin{array}{l}\text { Bilateral orbitofrontal cortex, R GPi, } \\
\text { medial frontal gyrus, L SMA, and } \\
\text { cingulate gyrus }\end{array}$ \\
\hline \multirow[t]{2}{*}{$\begin{array}{l}\text { Obermann } \\
\text { et al. (12) }\end{array}$} & $1.5 \mathrm{~T}$ & SPM2 & $12 \mathrm{~mm}$ & & $\mathrm{BSP}$ & 11 & 11 & $\begin{array}{l}<0.05 \\
\text { correct }\end{array}$ & Bilateral thalamus, putamen & Bilateral caudate head, cerebellum \\
\hline & & & & & $C D$ & 9 & 9 & $\begin{array}{l}<0.05 \\
\text { correct }\end{array}$ & $\begin{array}{l}\text { Bilateral putamen, superior } \\
\text { temporal lobule }\end{array}$ & $\begin{array}{l}\text { Bilateral caudate head, thalamus, } \\
\text { L posterior cerebellar lobe, and } \\
\text { superior temporal lobule }\end{array}$ \\
\hline $\begin{array}{l}\text { Suzuki } \\
\text { et al. (14) }\end{array}$ & $1.5 \mathrm{~T}$ & SPM8 & $9 \mathrm{~mm}$ & No & BSP & 32 & 48 & $\begin{array}{l}<0.05 \\
\text { correct }\end{array}$ & & $\begin{array}{l}\text { Bilateral sensory-motor cortices, } \\
\text { L cingulate }\end{array}$ \\
\hline $\begin{array}{l}\text { Martino } \\
\text { et al. (15) }\end{array}$ & $3 T$ & SPM8 & $8 \mathrm{~mm}$ & Yes & BSP & 25 & 24 & $\begin{array}{l}<0.05 \\
\text { correct } \\
<0.001 \\
\text { uncorrected }\end{array}$ & $\begin{array}{l}\text { L superior temporal gyrus, } \\
\text { postcentral gyrus }\end{array}$ & $\begin{array}{l}\text { R middle frontal gyrus } \\
\text { Bilateral superior frontal gyrus, } \\
\text { R middle frontal gyrus, L anterior } \\
\text { cingulate }\end{array}$ \\
\hline $\begin{array}{l}\text { Pantano } \\
\text { et al. (16) }\end{array}$ & $1.5 \mathrm{~T}$ & SPM5 & $12 \mathrm{~mm}$ & Yes & $C D$ & 19 & 28 & $\begin{array}{l}<0.05 \\
\text { correct }\end{array}$ & $\begin{array}{l}\text { Bilateral premotor and primary } \\
\text { sensory-motor cortices, L caudate } \\
\text { head, putamen }\end{array}$ & \\
\hline $\begin{array}{l}\text { Prell } \\
\text { et al. (11) }\end{array}$ & $1.5 \mathrm{~T}$ & SPM2 & $8 \mathrm{~mm}$ & Yes & $C D$ & 24 & 24 & $\begin{array}{l}<0.001 \\
\text { uncorrected }\end{array}$ & $\begin{array}{l}\text { L precentral, SMA, medial } \\
\text { temporal gyrus, and R } \\
\text { somatosensory association cortex }\end{array}$ & $\begin{array}{l}\text { L GPi, frontal eye field, R claustrum, } \\
\text { putamen, and bilateral medial } \\
\text { surface of occipital lobe }\end{array}$ \\
\hline
\end{tabular}

FWHM, full width half maximum; Mod, modulation; Dys, type of dystonia; PTS, number of patients; dIPFC, dorsolateral prefrontal cortex; GPi, globus pallidus internus.

characterize them using the most recent version of the software for VBM analysis as well as a larger sample.

\section{MATERIALS AND METHODS \\ SUBJECTS}

The Institutional Review Board of our University Hospital approved the study, and all subjects signed an informed consent prior to participation.

We included 27 subjects (mean age of $54.18 \pm 11.70$ years) with a clinical diagnosis of idiopathic CCD recruited at the Movement Disorders Outpatient Clinic, the Dystonia Outpatient Clinic, and the Neurogenetic Service of the University of Campinas (UNICAMP) University Hospital. All patients included were negative for DYT-1 and DYT-6 mutations. We performed a detailed clinical evaluation, which included a review of the medical history, duration of botulinum toxin treatment (BoNT), physical and neurological examination, and the Marsden-Fahn Scale (MFS). When conducting the MRI exam, all patients were at the peak of action of botulinum toxin, so that the images were obtained with a lower chance of motion artifacts. All clinical data are detailed in Table 2. The clinical presentation of dystonia is described in Table 3.

We included 54 healthy controls, with no history of neurological disorders, no family history of dystonia, and a normal neurological
Table 2 | Clinical data of patients and control subjects.

\begin{tabular}{lcc}
\hline & Patients & Controls \\
\hline Gender (male) & 9 & 18 \\
$\quad$ (female) & 18 & 36 \\
Age (years) & $54.18 \pm 11.70(29-75)$ & $54.00 \pm 11.47(29-77)$ \\
Disease duration (years) & $11.37 \pm 6.78(2-27)$ & - \\
BoNT (years) & $4.20 \pm 3.82(0-12)$ & - \\
MSF score & $5.13 \pm 2.61(2.5-10.5)$ & -
\end{tabular}

BoNT, botulinum toxin treatment duration; MSF score, score in Marsden-Fahn scale.

examination (mean age of $53.92 \pm 11.47$ years). Each patient was matched with two control subjects of the same gender and age of at most 2 years apart.

\section{MRI ACOUISITION}

Images were acquired at a 3 T Achieva MR unit-PHILIPS Intera ${ }^{\circledR}$, release 2.6.1.0. In addition to the usual diagnostic sequences, we obtained volumetric T1-weighted image, with isotropic voxels of $1 \mathrm{~mm}^{3}$, acquired in the sagittal plane ( $1 \mathrm{~mm}$ thick, flip angle, $8^{\circ}$, TR 7.1, TE 3.2, matrix $240 \times 240$, and FOV $240 \times 240 \mathrm{~mm}$ ). 
Table 3 | Clinical presentation of CCD in study participants.

\begin{tabular}{llcr}
\hline Distribution & Localization & N patients & $\%$ \\
\hline Focal & Cervical (C) & 13 & 48.1 \\
& Blepharospasm (B) & 2 & 7.4 \\
& Oromandibular (O) & 2 & 7.4 \\
Segmental & B + O & 3 & 11.1 \\
& B + O + C & 5 & 18.5 \\
& O + C & 1 & 3.7 \\
Total & O +laryngeal & 1 & 3.7 \\
& Total & 27 & $100 \%$ \\
\hline
\end{tabular}

\section{IMAGE PRE-PROCESSING}

Prior to any imaging processing, an experienced neuroradiologist evaluated all images in a blinded fashion for controls and patients, to assure image quality and the absence of significant brain pathology or artifacts. Then, we aligned all the images according to the anterior commissure and rotated those images in the sagittal, axial, and coronal planes according to the same references, when necessary, in order to provide the most homogeneous sample possible.

\section{VOXEL-BASED MORPHOMETRY ANALYSIS}

The VBM processing entailed four main steps: spatial normalization of all images to the same stereotactic space, segmentation into GM, white matter, and cerebrospinal fluid, re-slicing into an atlas space (modulation), and smoothing. The difference between our previous and present study is that in the first one our aim was to investigate morphological changes of the cerebellum, since functional studies had reported abnormalities in dystonic patients. For this purpose, we used the spatially unbiased infratentorial template (SUIT tool), which isolates the infratentorial structure from the surrounding tissue before the spatial normalization of VBM. The idea was to prevent the supratentorial structures from biasing the results. Moreover, the normalization with the SUIT template avoids the stretching of the cerebellum in $z$-direction and leads to a better overlap between the cerebellar lobules. Therefore, the present study aims to complement the previous one, using a wholebrain template since the supratentorial areas are also involved in the pathophysiology of CCD.

In the present study, the images were automatically normalized, segmented, and modulated by SPM8 (Statistical Parametric Mapping) from MATLAB R2011b platform, according to technical and methodological protocols (www.fil.ion.ucl.ac.uk/spm/). The modulation compensates for the effect of the non-linear spatial normalization by multiplying the voxel intensities for the local value in the deformation field from normalization. This procedure allows the use of a small filter in the smoothness and the measurement of GM volume instead of GM density only. We next performed a homogeneity test to check the standard deviation across the sample using the covariance of the images. We also re-sliced the images by interpolation of the voxels in order to generate a final voxel size of $1 \mathrm{~mm}^{3}$. Finally, the GM probability images were smoothed with $10 \mathrm{~mm}$ full width half maximum (FWHM) isotropic Gaussian kernel filter in SPM8/DARTEL to satisfy the Gaussian distribution assumption for statistical analysis of regional differences. This process minimizes effects due to residual differences in functional and gyral anatomy during intersubject
Table 4 | Areas of decreased GM using $p<0.001$

\begin{tabular}{|c|c|c|c|c|}
\hline \multicolumn{5}{|c|}{ Gray matter (decrease) $p<0.001$} \\
\hline \multicolumn{3}{|c|}{$\begin{array}{c}\text { MNI peak } \\
\text { co-ordinates }\end{array}$} & \multirow[b]{2}{*}{ Voxels } & \multirow[b]{2}{*}{ Areas (automated anatomical labeling) } \\
\hline $\boldsymbol{x}$ & $y$ & $z$ & & \\
\hline \multirow[t]{4}{*}{2} & 40 & -3 & 1151 & Left anterior cingulate and paracingulate gyrus \\
\hline & & & 366 & Right anterior cingulate and paracingulate gyrus \\
\hline & & & 97 & Right superior frontal gyrus, orbital part \\
\hline & & & 88 & Left superior frontal gyrus, orbital part \\
\hline \multirow[t]{6}{*}{-34} & 4 & -14 & 1006 & Left temporal pole of superior temporal gyrus \\
\hline & & & 818 & Left insula \\
\hline & & & 779 & Left superior temporal gyrus \\
\hline & & & 351 & Left inferior frontal gyrus, orbital part \\
\hline & & & 153 & Left rolandic operculum \\
\hline & & & 97 & Left inferior frontal gyrus, opercular part \\
\hline \multirow[t]{9}{*}{0} & -53 & 24 & 966 & Left precuneus \\
\hline & & & 678 & Cerebellar vermic lobule IVN \\
\hline & & & 644 & Left Calcarine fissure \\
\hline & & & 512 & Left lingual gyrus \\
\hline & & & 275 & Right lingual gyrus \\
\hline & & & 191 & Right Calcarine fissure \\
\hline & & & 188 & Left posterior cingulate \\
\hline & & & 160 & Right precuneus \\
\hline & & & 59 & Left cerebellar lobules IVN \\
\hline \multirow[t]{2}{*}{-34} & -73 & 6 & 656 & Left middle occipital gyrus \\
\hline & & & 74 & Left middle temporal gyrus \\
\hline-30 & 30 & -14 & 419 & Left inferior frontal gyrus, orbital part \\
\hline-60 & -51 & 2 & 397 & Left middle temporal gyrus \\
\hline 38 & 16 & -15 & 226 & Right insula \\
\hline \multirow[t]{2}{*}{-10} & -41 & 2 & 156 & Left lingual gyrus \\
\hline & & & 91 & Left precuneus \\
\hline-8 & -1 & 64 & 145 & Left supplementary motor area \\
\hline-22 & -9 & -13 & 112 & Left hippocampus \\
\hline \multirow[t]{2}{*}{-58} & 31 & 21 & 108 & Left supramarginal gyrus \\
\hline & & & 80 & Left superior temporal gyrus \\
\hline-40 & -57 & 47 & 96 & Left inferior parietal gyrus \\
\hline 14 & -24 & 75 & 80 & Right precentral gyrus \\
\hline 2 & -17 & 49 & 65 & Right middle cingulate \\
\hline
\end{tabular}

Height threshold: $T=3.16$; Extend threshold $=100$ voxels; voxel size $=1 \mathrm{~mm}^{3}$; FWHM Gaussian filter $=10 \mathrm{~mm}$.

averaging and renders the data more normally distributed. As our analysis is based on unbalanced sample sizes, a filter with a greater extent is needed to avoid a greater number of false positives. Considering that our subjects are matched and $p<0.001$, we used a FWHM of $10 \mathrm{~mm}$ instead of the $12 \mathrm{~mm}$ filter, due to the increased risk of false negative results (17). Using SPM8/DARTEL, a twosample $t$-test corrected for subjects' age was created for voxelby-voxel analysis and detection of GM differences between the groups. In the contrast manager, we determined one contrast for GM atrophy and one for GM excess. Two different statistical parametric maps were generated: one corrected for false discovery rate (FDR), $p<0.05$ and other for $p<0.001$ uncorrected. Automated anatomical labeling (AAL) was used for anatomical localizations. 


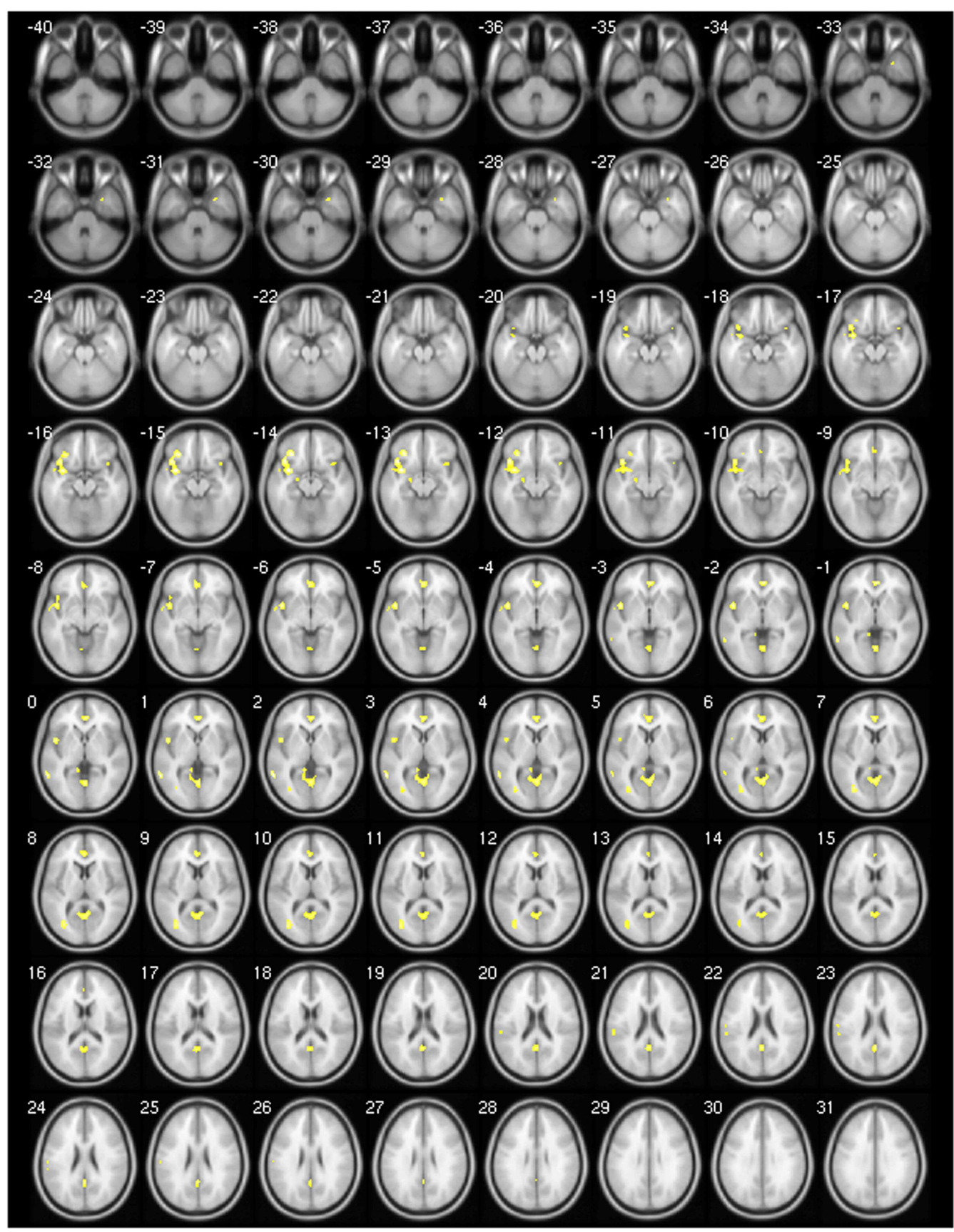

FIGURE 1 | Areas showing decreased GM in axial slices using $p<0.001$

We also attempted to correlate the GM volume of the patients with the following clinical data: age, disease duration, duration of BoNT, and the MFS score. This analysis was performed in SPM8 using separate regression analyses. In the contrast manager, we could establish positive and negative correlations.

\section{RESULTS}

We found decreased GM using $p<0.001$ and clusters $>50$ voxels in the cerebellar vermis IV/V, bilaterally in the superior frontal gyrus, precuneus, anterior cingulate and paracingulate, insular cortex, lingual gyrus, and calcarine fissure; in the left hemisphere in the supplementary motor area (SMA), inferior frontal gyrus (IFG), inferior parietal gyrus, temporal pole, supramarginal gyrus, rolandic operculum, hippocampus, middle occipital gyrus, cerebellar lobules IV/V, superior, and middle temporal gyri; and finally, in the right hemisphere, the middle cingulated and precentral gyrus (Table 4; Figure 1). 
In order to refine our analysis, we performed the same analysis using FDR correction $(p<0.05)$, but we did not find any significant cluster of decreased or increased GM. In addition, there were no significant clusters of GM increased in both analysis using $p<0.001$ and FDR correction.

We observed a negative correlation between GM volume and age in the left basal ganglia, olfactory cortex, hippocampus, lingual gyrus, and bilaterally in the cingulate; between GM volume and disease duration in the cerebellar lobules crus I, crus II, VII, VIIb, and VIII, in the left precuneus and middle frontal gyrus; between GM volume and BoNT in the left inferior temporal gyrus and between GM volume and MFS in the right inferior temporal gyrus, postcentral, and left rolandic operculum. There was a positive correlation between GM volume and disease duration in the cerebellar lobule VIII; between GM volume and BoNT in the left IFG, fusiform gyrus, superior parietal gyrus, postcentral gyrus, and cerebellar lobule IV/V and between GM volume and MFS in the left olfactory cortex and right precentral gyrus (Table 5).

\section{DISCUSSION}

Our results reveal decreased GM mostly in the premotor cortex (PMC), somatosensory integration areas, anterior cingulated/paracingulate, and cerebellum. Our findings were slightly more prominent in the left hemisphere, and we failed to detect any abnormality in the basal ganglia. These results share some interesting similarities with the most recent reports, while very discrepant ones from older studies. From the eight published studies in CCD using VBM (9-16), the earlier ones show varying results regarding increase and decrease in GM in the basal ganglia, while the later ones have not shown any abnormality in the basal ganglia $(14,15)$. Areas with consistent GM that decreases between the present study and prior ones are the $\operatorname{SMA}(9,11,16), \operatorname{PMC}(9,16)$, precentral gyrus $(11,15,16)$, inferior parietal gyrus (13), superior temporal gyrus (12), visual cortex (9), precuneus, and the middle temporal gyrus (11). A recent abstract described decreased GM density in the rolandic operculum and insula in patients with CD and decreased GM in the precentral gyrus, cerebellum, operculum, cingulum, lingual gyri, and hippocampus in patients with BSP (18). There was also no atrophy in the basal ganglia or areas of GM increase.

Several possible explanations may account for the abovementioned discrepancies. First, there were multiple updates in the software used to perform the VBM analysis as well as new methodological protocols for VBM processing. Second, the widespread use of $3 \mathrm{~T}$ or stronger MRI scanners renders a more detailed and trustworthy image than the $1.5 \mathrm{~T}$ analysis that was used by seven of the eight previous studies $(9-14,16)$. Their difference in the VBM process, however, has never been definitely substantiated by later publications (19). Third, we used a larger control group to increase power. Prior studies mostly included one type of focal dystonia, either CD $(9,11,12,16)$ or BSP $(12-15)$. Our study population was more heterogeneous and included individuals with broader clinical manifestations, including some never previously studied by imaging (such as oromandibular dystonia) and not only focal but also segmental dystonias. Our less restrictive inclusion criteria likely increase the external validity of our results, without compromising its internal one.
Table 5 | Clinical correlation using $p<0.001$ and $k>100$ voxels.

Clinical correlation $p<0.001$

\begin{tabular}{ccccc}
\hline \multicolumn{3}{c}{$\begin{array}{c}\text { MNI peak } \\
\text { co-ordinates }\end{array}$} & & \\
\cline { 1 - 2 } & $y$ & $z$ & Voxels & $\begin{array}{l}\text { Areas (automated anatomical } \\
\text { labeling) }\end{array}$ \\
& & &
\end{tabular}

Positive correlation: age and gm

No significant

\begin{tabular}{|c|c|c|c|c|}
\hline \multicolumn{5}{|c|}{ Negative correlation: age and gm } \\
\hline \multirow[t]{3}{*}{-18} & 6 & -14 & 175 & Left olfactory cortex \\
\hline & & & 122 & Left caudate nucleus \\
\hline & & & 101 & Left lenticular nucleus, putamen \\
\hline \multirow[t]{2}{*}{2} & 30 & -2 & 879 & Left anterior cingulate \\
\hline & & & 849 & Right anterior cingulate \\
\hline-20 & -38 & -1 & 182 & Left hippocampus \\
\hline 8 & -58 & 1 & 100 & Right lingual gyrus \\
\hline
\end{tabular}

Positive correlation: disease duration and gm

$\begin{array}{rrrrl}-20 & -53 & -40 & 400 & \text { Left cerebellar lobule VIII } \\ 14 & -64 & -37 & 782 & \text { Right cerebellar lobule VIII }\end{array}$

\section{negative correlation: disease duration and gm}

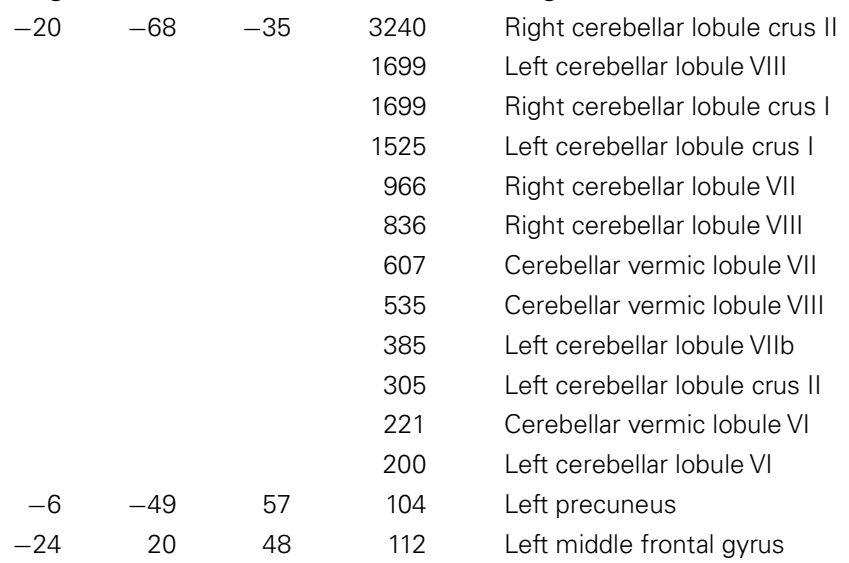

Positive correlation: bont and gm

$\begin{array}{llll}-32 & -23 & -27 & 141\end{array}$

$\begin{array}{llll}-22 & -40 & -22 & 126\end{array}$

$\begin{array}{llll}-46 & 20 & 48 & 304\end{array}$

$\begin{array}{llll}-22 & -56 & 43 & 201\end{array}$

$\begin{array}{llll}-38 & -314 & 50 & 481\end{array}$

Left fusiform gyrus

Left cerebellar lobule IVN

Left inferior frontal gyrus,

triangular part

Left superior parietal gyrus

Left postcentral gyrus

Negative correlation: bont and gm

$\begin{array}{llll}-46 & -17 & -22 & 140\end{array}$

Left inferior temporal gyrus

Positive correlation: $\mathbf{m f s}$ and gm

$\begin{array}{llll}0 & -83 & 23 & 198\end{array}$

$\begin{array}{llll}46 & 2 & 59 & 260\end{array}$

Left olfactory cortex

Right precentral gyrus

Negative correlation: $\mathbf{m f s}$ and gm

$\begin{array}{rrrr}48 & -28 & -23 & 280 \\ -46 & -12 & 13 & 104 \\ 54 & -19 & 36 & 193\end{array}$

Right inferior temporal gyrus

Left rolandic operculum

Right postcentral gyrus 


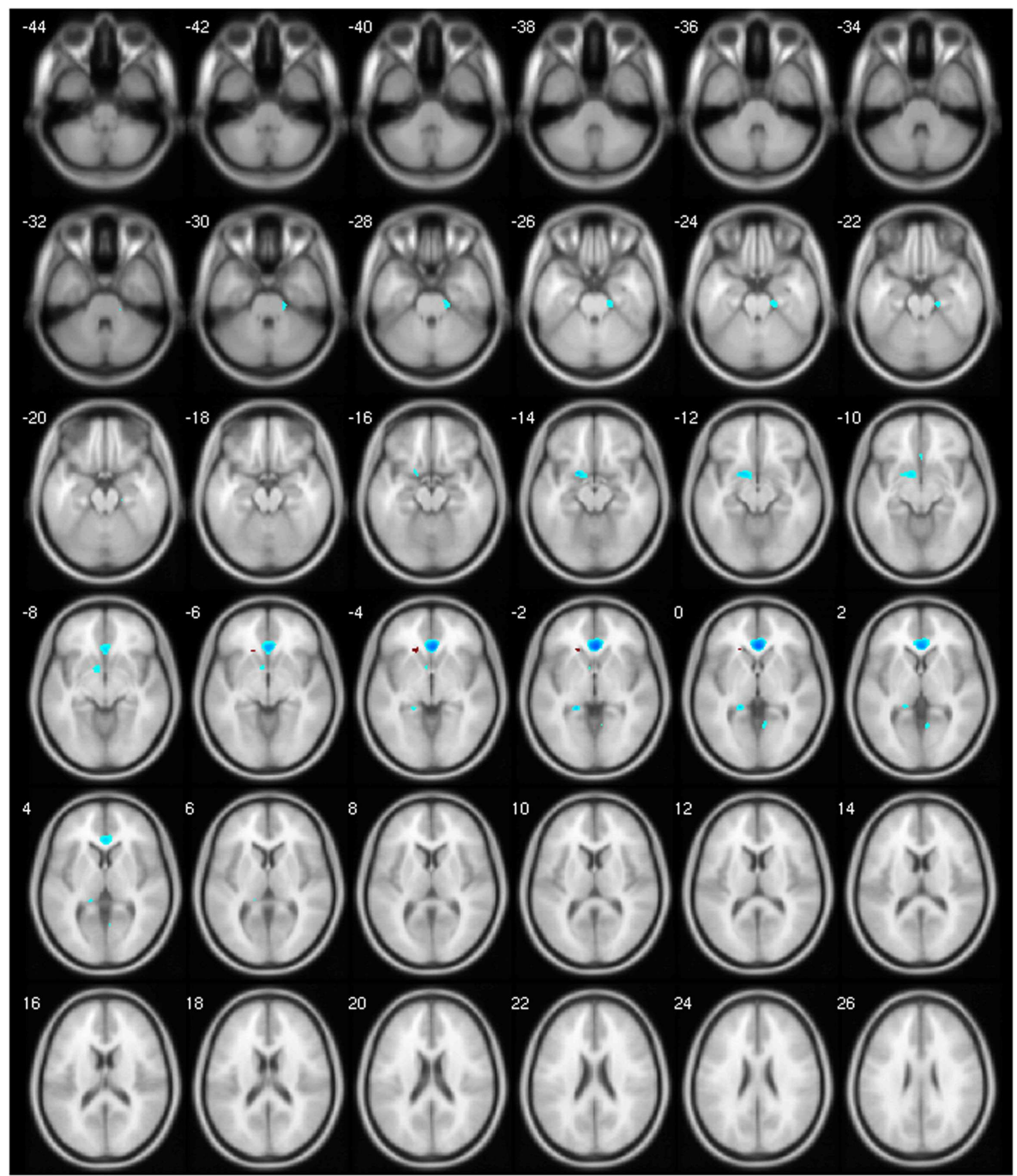

FIGURE 2 | Negative correlation between age and GM volume

The precentral gyrus is involved in the execution of movements by activation of the motorneurons. The SMA and the premotor area are responsible for motor sequencing and planning (20). Information cascades downwards from the supramodal prefrontal cortex (PFC) to the primary motor cortex converting abstract goals in the PFC into motor plans in the premotor system. Thus, the PFC seems to play an important role in motor planning and learning (21). The PFC seems also to participate in changes or stops in voluntary movements by the inhibitory orbitofrontal impulses (22). The pars opercularis of the IFG is known for its role in speech production as well as speech programing and possibly the fluency and sequencing of the speech (23).

We found significant structural changes in the rolandic operculum, where the secondary somatosensory cortex resides and in the precuneus (mesial extent of Brodmann's area 7 - part of somatosensory association cortex). Patients with CCD have abnormalities in the structures subserving sensation demonstrated by several studies using fMRI, PET, and electrophysiological techniques (24-26), while subjects with CD and BSP demonstrated a significant increase of spatial discrimination thresholds in both hands, suggesting abnormal sensory processing (27). Conversely, sensory tricks are considered a clinical manifestation of sensory involvement. The insular cortex is anatomically an elongation of the secondary somatosensory cortex and it is functionally connected to it as well as to the adjacent primary somatosensory cortex (28). The insula plays a central role in pain perception (29). Despite this sensory modality being rarely addressed in imaging studies in dystonia, it is a frequent symptom in dystonia, especially in CD. The abnormal responsiveness of the sensory-motor cortex seems to be driven by an unbalanced mechanism between long-term potentiation and long-term depression, leading to a maladaptative neuroplasticity activity, which is difficult to depotentiate in the motor cortex. The consolidation of abnormal motor engrams due to this mechanism may culminate in the overt muscular contraction observed in dystonic patients (30). 


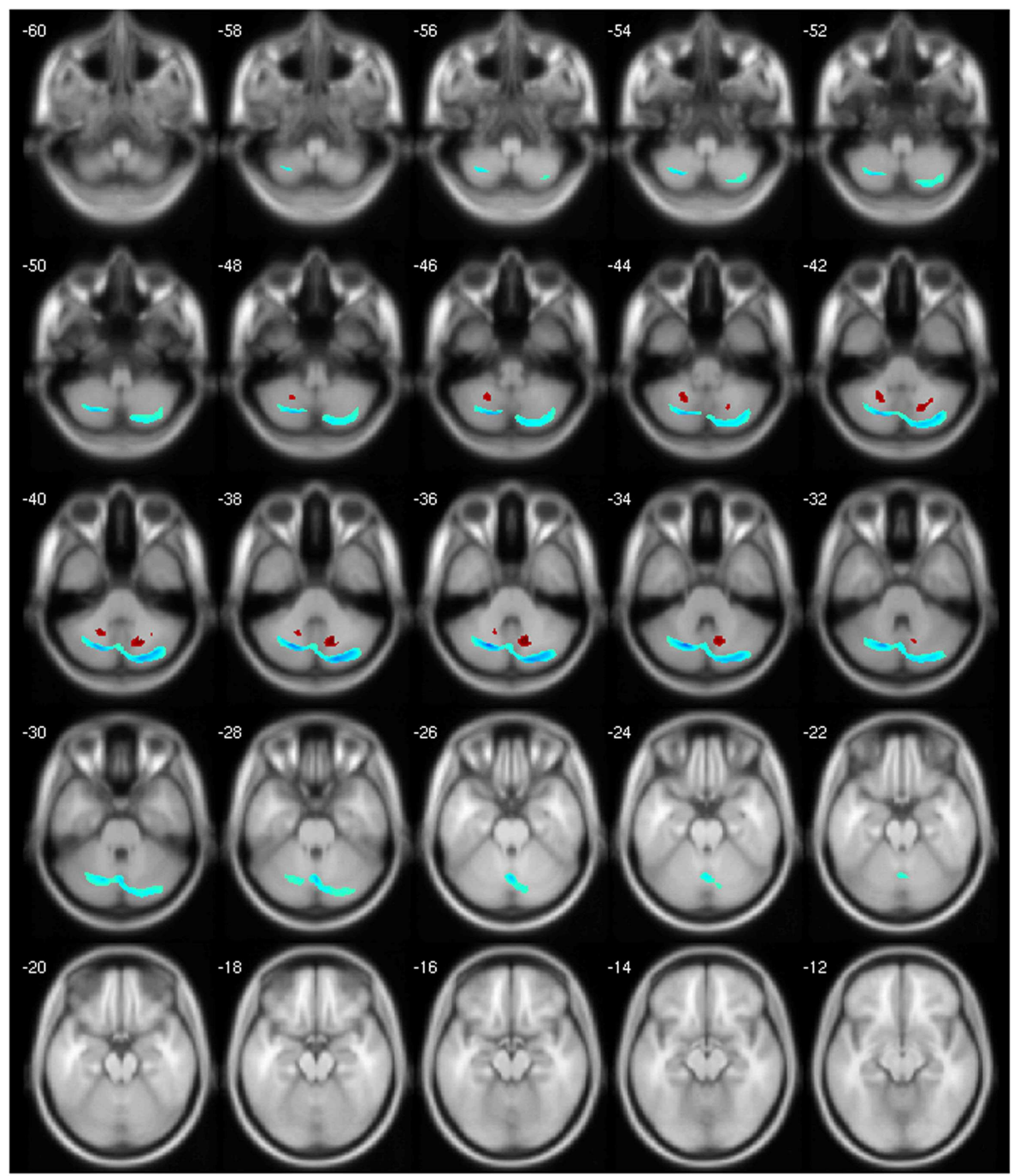

FIGURE 3 | Negative (blue) and positive (red) correlation between disease duration and GM volume.

The sensorimotor network (SMN) comprised regions in the PFC, PMC, primary sensorimotor cortex (SM1), and the secondary somatosensory cortex, including the superior parietal lobule. We did not find any changes in the SM1. However, our study revealed small clusters of GM decrease in this area (data not shown) that might reach significance in a larger sample. This network seems to correspond mostly with the action-execution and perceptual-somesthesis paradigms $(31,32)$. The primary visual network (PVN) includes the PFC, PMC, SM1, superior parietal lobule, paracingulate gyrus, visual cortex, and middle temporal gyrus. Our study detected extensive GM decrease in both sensorimotor and PVNs. In CD, a task-free fMRI study showed decreased connectivity within these networks (33), and VBM, magnetization transfer imaging, and fractional anisotropy analyses presented changes in the visual areas $(9,11)$.

The PVN plays an important role in visual perception and processing of spatial information. Together with the frontoparietal network, they are responsible for building a representation of the space, in which spatial body knowledge is integrated from visual, proprioceptive, and somatosensory information, all crucial for accurate movement (34). The cingulate and precuneus are critical structures for the proper performance of the visuospatial system. Recent functional imaging findings suggest a central role for the precuneus in a wide spectrum of highly integrated tasks including spatial relations for body movement control (motor imagery) (35). Subjects with idiopathic dystonia have significant visuospatial function deficits (36) and the decreased connectivity within this system may manifest as abnormal head posture or movements (33).

We observed GM decreases in structures that are functionally associated with emotional processing and psychiatric disorders. Sixty percent of subjects with dystonia show psychiatric symptoms, and $42-71 \%$ of them developed those prior to the motor ones (37-39). As we did not perform a detailed 


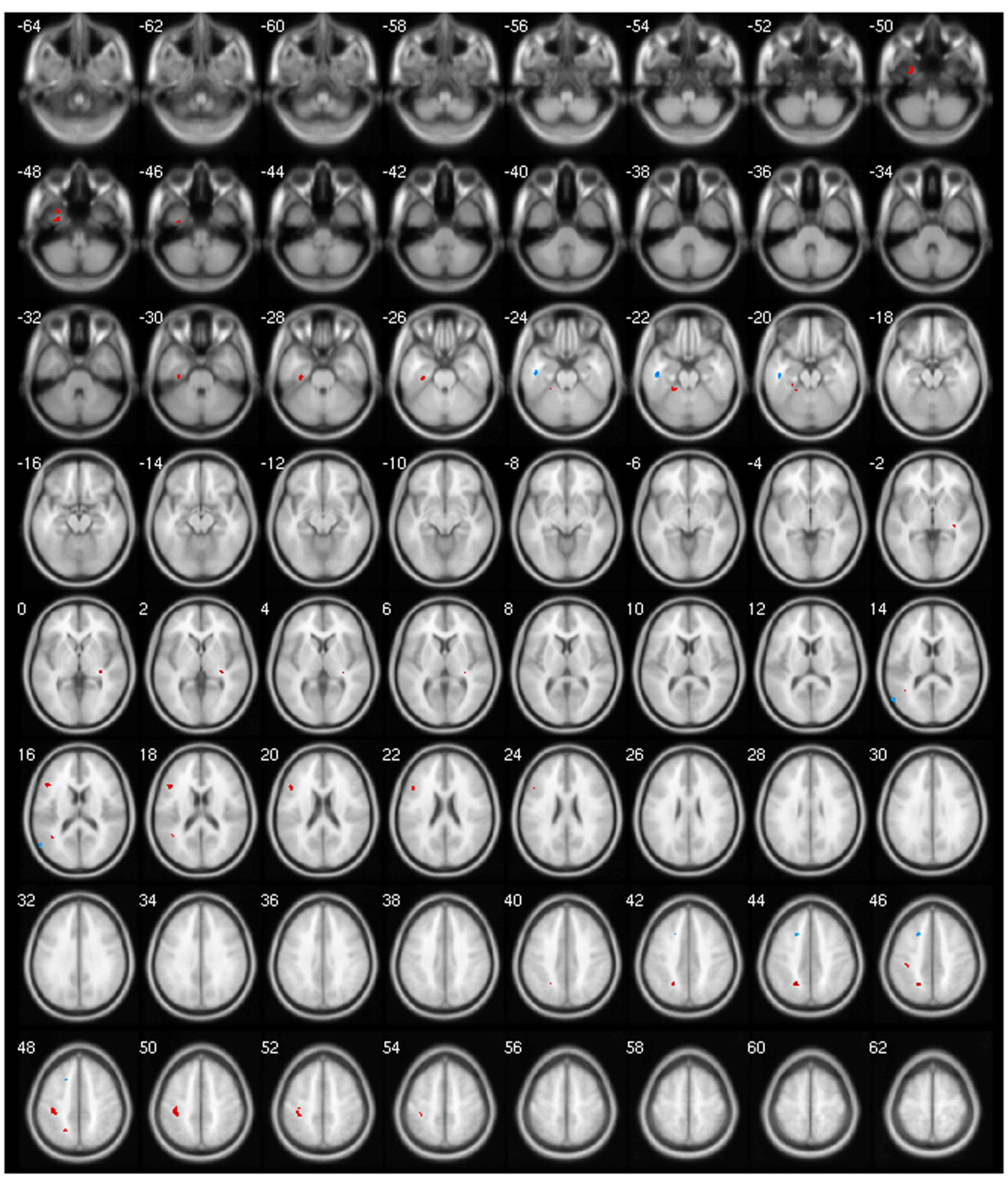

FIGURE 4 | Negative (blue) and positive (red) correlation between BoNT duration and GM volume

neuropsychiatric evaluation, we cannot comment on this possible correlation.

The lack of substantial basal ganglia involvement in dystonia is not necessarily surprising. VBM is not the most accurate neuroimaging technique to verify morphometric changes in the deep cerebral GM. Earlier VBM studies reported contradictory results, with some showing GM reduction $(12,16)$ and others GM increase $(12,13)$. It is possible that, albeit a functional involvement of the basal ganglia is necessary to the development and the maintenance of the dystonic movement, an anatomical one is not imperative. Secondary dystonia may develop in subjects without basal ganglia damage $(40,41)$. Moreover, studies after basal ganglia lesions observed delays in symptom onset from weeks to years, indicating that the loss of function was not directly a consequence of the lesion itself, but rather from the process of neuroplasticity (42).

The regions of cerebellar involvement are a little different from our recent evaluation of the cerebellum using the SUIT tool for VBM in which we detected GM increase in the left cerebellar hemispheres I-IV and GM decrease bilaterally in the lobule VI, crus I, 


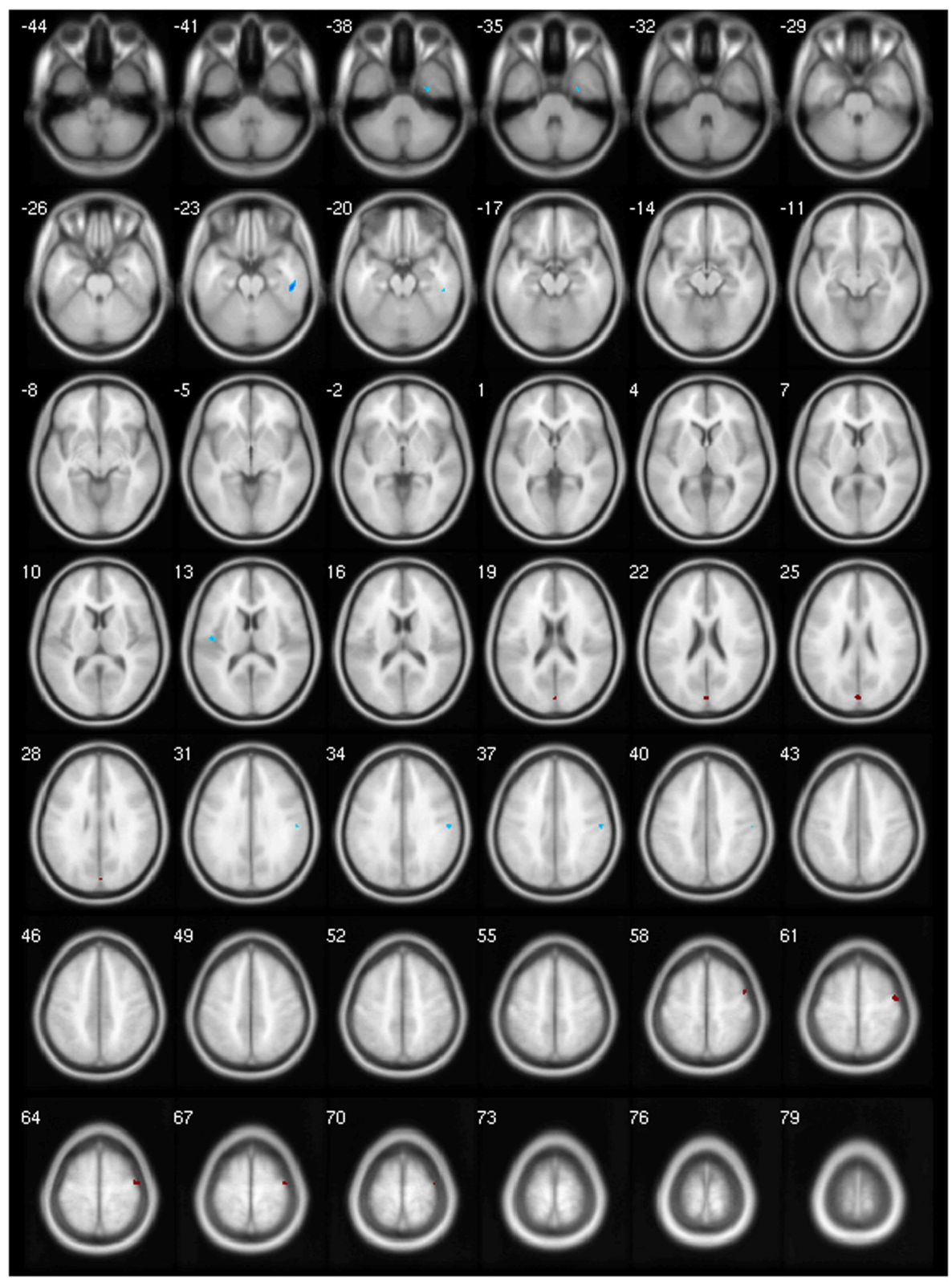

FIGURE 5 | Negative (blue) and positive (red) correlation between MSF score and GM volume

and right lobule VIIIb (7). In the first study, we used a specific tool for the cerebellum, since it provides a better overlap of the cerebellar lobules, preserves the anatomical detail, and does not allow the supratentorial structures to bias the results.

Finally, our clinical correlation showed some significant associations. The correlation between GM volume and age was negative for several areas, which we expected, since several VBM studies have identified age-related neocortical and subcortical volume reductions during adult life (43) (Figure 2). GM volume and disease duration were negatively correlated with the cerebellar lobules crus I, crus II, VII, VIIb, and VIII, in the left precuneus and middle frontal gyrus and positively correlated with cerebellar lobule
VIII (Figure 3). The negative correlation between GM volume and the posterior cerebellar lobules reinforces the role of the cerebellum in dystonia as previously mentioned and published (7). Moreover, the correlation found suggests that the maintenance of dystonic movements has a negative impact in the cerebellar function leading to GM atrophy, which might be secondary to the circuit dysfunction. However, most of the previous studies failed to detect any clinical correlation. There is one longitudinal study only, which found GM decrease in the sensorimotor area in the 5 -year follow-up (16). Therefore, further clinical correlation and longitudinal studies, as well as connectivity studies should be performed in order to clarify the trend of decreasing GM volume. 
GM volume and duration of BoNT were negatively correlated in the left inferior temporal gyrus but positively in the left fusiform, superior parietal, post central gyri, IFG, and cerebellar lobule IV/V (Figure 4). Delnooz et al. performed a longitudinal study comparing patients pre- and post-BoNT and showed an increased GM in patients post-treatment in the right dorsal PMC, inferring that BoNT is able to induce GM changes (44). Higher scores at MFS also showed both, a positive correlation in the left olfactory cortex and right precentral gyrus and a negative correlation in right inferior temporal gyrus, postcentral gyus, and left rolandic operculum (Figure 5). It is very interesting to observe that subjects with more severe disease have more atrophy at the postcentral gyrus.

The major limitation in our study is the heterogeneous collection of dystonias. However, there is a significant clinical overlap between those forms of dystonia, which is observable in subjects with progression of the dystonia to continuous segments. Some studies have also studied CCD as a group (2-7). Our aim was not to evaluate the differences between those, but rather to elucidate common mechanisms in the pathophysiology of CCD, which could even be hypothesized in other presentations, such as taskspecific and focal hand dystonia $(45,46)$. Another limitation is the lack of proper clinical characterization of the side of the symptoms and documentation of hand dominance in our subjects. Previous studies showed asymmetrical interhemispheric activity along the direct pathway within the basal ganglia (47). A technical limitation is that the SUIT tool used in our previous analysis cannot be combined with the whole-brain template, which led us to perform two separate analyses. Unfortunately, our results can only be considered exploratory, since, a more strict correction (FDR and FWE) did not reveal any significant result.

\section{CONCLUSION}

We detected diffuse involvement in CCD. The GM changes in the premotor, motor, and somatosensory cortex corroborate the disorganization of the SMN. The structural involvement of the frontoparietal network, the visual areas, the precuneus, and the cingulated are potentially involved in the visuospatial impairment presented in patients with dystonia and have been recently described by several authors. Finally, the insula, the limbic system, and the cerebellum elucidate possible contributory mechanisms in the pathophysiology of the dystonia. Nonetheless, it is unclear if the GM findings observed are primary or secondary, and further longitudinal studies may be better suited to answer this question.

\section{AUTHOR CONTRIBUTIONS}

(1) Research project: A. conception: Anelyssa D’Abreu; Camila C. Piccinin; Maria C. A. Santos; Iscia Lopes-Cendes; Fernando Cendes. B. organization: Anelyssa D’Abreu; Camila C. Piccinin; Maria C. A. Santos. C. execution: Camila C. Piccinin; Maria C. A. Santos; Luiza G. Piovesana; Lidiane S. Campos; Rachel P. Guimarães; Brunno M. De Campos; Thiago J. R. Rezende; Fabio R. Torres; Marcondes C. França Jr.; Augusto C. Amato-Filho/Anelyssa D’Abreu. (2) Statistical analysis: A. design: Anelyssa D'Abreu; Brunno M. De Campos; Rachel P. Guimarães; Luiza G. Piovesana; Fabio R. Torres; Thiago J. R. Rezende; Iscia Lopes-Cendes; Fernando Cendes. B. execution: Camila C. Piccinin; Maria C. A. Santos; Brunno M. De Campos; Luiza G. Piovesana; Rachel P.
Guimarães. C. review and critique: Anelyssa D'Abreu; Marcondes C. França Jr.;Thiago J. R. Rezende; Iscia Lopes-Cendes; Fernando Cendes. (3) Manuscript: A. writing of the first draft: Camila C. Piccinin; Anelyssa D’ Abreu. B. review and critique: Anelyssa D’Abreu; Iscia Lopes-Cendes; Fernando Cendes; Luiza G. Piovesana; Lidiane S. Campos; Rachel P. Guimarães; Fabio R. Torres; Marcondes C. França Jr.; Augusto C. Amato-Filho.

\section{ACKNOWLEDGMENTS}

We would like to thank Dr. J.H. Friedman for his valuable suggestions and for kindly reviewing this manuscript. Funding statement: This work was supported by FAPESP (São Paulo Research Foundation), grant number 2010/11085-9. Financial disclosures of all authors: Camila C. Piccinin: research grant from FAPESP. Maria C. A. Santos: research grant from FAPESP. Rachel P. Guimarães: research grant from FAPESP. Luiza G. Piovesana: educational grant from Ipsen. Brunno M. De Campos: none. Thiago J. R. Rezende: none. Lidiane S. Campos: educational grant from Ipsen. Fabio R. Torres: supported by a Post-doctoral fellowship from CAPES, BRAZIL. Marcondes C. França Jr.: none. Augusto C. Amato-Filho: none. Iscia Lopes-Cendes: supported by grants from FAPESP and CNPq, BRAZIL. Fernando Cendes: supported by grants from FAPESP and CNPq, BRAZIL. Anelyssa D'Abreu: travel grant from ROCHE; lecture fees from Novartis; consulting fees from EMS; Research grant from FAPESP and CNPq, Brazil.

\section{REFERENCES}

1. Albanese A, Bhatia K, Bressman SB, Delong MR, Fahn S, Fung VS, et al. Phenomenology and classification of dystonia: a consensus update. Mov Disord (2013) 28:863-73. doi: $10.1002 / \mathrm{mds} .25475$

2. Colosimo C, Suppa A, Fabbrini G, Bologna M, Berardelli A. Craniocervical dystonia: clinical and pathophysiological features. Eur J Neurol (2010) 17:15-21. doi:10.1111/j.1468-1331.2010.03045.x

3. Colosimo C, Tiple D, Berardelli A. Efficacy and safety of long-term botulinum toxin treatment in craniocervical dystonia: a systematic review. Neurotox Res (2012) 22:265-73. doi:10.1007/s12640-012-9314-y

4. Charlesworth G, Plagnol V, Holmström KM, Bras J, Sheerin UM, Preza E, et al. Mutations in ANO3 cause dominant craniocervical dystonia: ion channel implicated in pathogenesis. Am J Hum Genet (2012) 91:1041-50. doi:10.1016/j.ajhg. 2012.10.024

5. Müller J, Wissel J, Kemmler G, Voller B, Bodner T, Schneider A, et al. Craniocervical dystonia questionnaire (CDQ-24): development and validation of a disease-specific quality of life instrument. J Neurol Neurosurg Psychiatry (2004) 75:749-53. doi:10.1136/jnnp.2003.013441

6. Bradnam L, Barry C. The role of the trigeminal sensory nuclear complex in the pathophysiology of craniocervical dystonia. J Neurosci (2013) 33:18358-67. doi:10.1523/JNEUROSCI.3544-13.2013

7. Piccinin C, Santos M, Piovesana L, Campos L, Guimarães R, Campos B, et al. Infratentorial gray matter atrophy and excess in primary craniocervical dystonia. Parkinsonism Relat Disord (2014) 20:198-203. doi:10.1016/j.parkreldis.2013.10. 026

8. Ashburner J, Friston KJ. Voxel-based morphometry - the methods. Neuroimage (2000) 11:805-21. doi:10.1006/nimg.2000.0582

9. Draganski B, Thun-Hoheinstein C, Bogdahn U, Winkler J, May A. "Motor circuit" gray matter changes in idiopathic cervical dystonia. Neurology (2003) 61:1228-31. doi:10.1212/01.WNL.0000094240.93745.83

10. Egger K, Mueller J, Schocke M, Rinnerthaler M, Seppi K, Trieb T, et al. Voxel based morphometry reveals specific gray matter changes in primary dystonia. Mov Disord (2007) 22:1538-42. doi:10.1002/mds.21619

11. Prell T, Peschel T, Köhler B, Bokemeyer MH, Dengler R, Günther A, et al. Structural brain abnormalities in cervical dystonia. BMC Neurosci (2013) 14:123. doi:10.1186/1471-2202-14-123 
12. Obermann M, Yaldizli O, De Greiff A, Lachenmayer M, Buhl A, Tumczac F, et al. Morphometric changes of sensorimotor structures in focal dystonia. Mov Disord (2007) 22:1117-23. doi:10.1002/mds.21495

13. Etgen T, Mühlau M, Gaser C, Sander D. Bilateral grey-matter increase in the putamen in primary blepharospasm. J Neurol Neurosurg Psychiatry (2006) 77:1017-20. doi:10.1136/jnnp.2005.087148

14. Suzuki Y, Kiyosawa M, Wakakura M, Mochizuki M, Ishii K. Gray matter density increase in the primary sensorimotor cortex in long-term essential blepharospasm. Neuroimage (2011) 56:1-7. doi:10.1016/j.neuroimage.2011.01.081

15. Martino D, Di Giorgio A, D’Ambrosio E, Popolizio T, Macerollo A, Livrea $\mathrm{P}$, et al. Cortical gray matter changes in primary blepharospasm: a voxel-based morphometry study. Mov Disord (2011) 26:1907-12. doi:10.1002/ mds. 23724

16. Pantano P, Totaro P, Fabbrini G, Raz E, Contessa GM, Tona F, et al. A transverse and longitudinal MR imaging voxel-based morphometry study in patients with primary cervical dystonia. AJNR Am J Neuroradiol (2011) 32:81-4. doi:10.3174/ajnr.A2242

17. Mechelli A, Price CJ, Friston KJ, Ashburner J. Voxel-based morphometry of the human brain: methods and applications. Curr Med Imaging Rev (2005) 1:105-13. doi:10.2174/1573405054038726

18. Sarro L, Agosta F, Tomic A, Kresojevic N, Caso F, Svetel M, et al. Cortical gray matter changes in primary focal dystonia. Neurology (2013) 80(Meeting Abstracts 1):06.086.

19. Scorzin JE, Kaaden S, Quesada CM, Müller CA, Fimmers R, Urbach H, et al. Volume determination of amygdala and hippocampus at 1.5 and 3.0T MRI in temporal lobe epilepsy. Epilepsy Res (2008) 82:29-37. doi:10.1016/j.eplepsyres. 2008.06.012

20. Catalan MJ, Honda M, Weeks RA, Cohen LG, Hallett M. The functional neuroanatomy of simple and complex sequential finger movements: a PET study. Brain (1998) 121:253-64. doi:10.1093/brain/121.2.253

21. Ramnani N, Owen AM. Anterior prefrontal cortex: insights into function from anatomy and neuroimaging. Nat Rev Neurosci (2004) 5:184-94. doi:10.1038/ nrn 1343

22. Frank JM, Loughry B, O’Reilly RC. Interactions between frontal cortex and basal ganglia in working memory: a computational model. Cogn Affect Behav Neurosci (2001) 1:137-60. doi:10.3758/CABN.1.2.137

23. Amunts K, Weiss PH, Mohlberg H, Pieperhoff P, Eickhoff S, Gurd JM, et al. Analysis of neural mechanisms underlying verbal fluency in cytoarchitectonically defined stereotaxic space - the roles of Brodmann areas 44 and 45 . Neuroimage (2004) 22:42-56. doi:10.1016/j.neuroimage.2003.12.031

24. Niethammer M, Carbon M, Argyelan M, Eidelberg D. Hereditary dystonia as a neurodevelopmental circuit disorder: evidence from neuroimaging. Neurobiol Dis (2011) 42:202-9. doi:10.1016/j.nbd.2010.10.010

25. Obermann M, Vollrath C, de Greiff A, Gizewski E, Diener H, Hallett M, et al. Sensory disinhibition on passive movement in cervical dystonia. Mov Disord (2010) 25:2627-33. doi:10.1002/mds.23321

26. Stamelou M, Edwards MJ, Hallett M, Bhatia K. The non-motor syndrome of primary dystonia: clinical and pathophysiological implications. Brain (2012) 135:1668-81. doi:10.1093/brain/awr224

27. Molloy FM, Carr TD, Zeuner KE, Dambrosia JM, Hallett M. Abnormalities of spatial discrimination in focal and generalized dystonia. Brain (2003) 126:2175-82. doi:10.1093/brain/awg219

28. Deen B, Pitskel NB, Pelphrey KA. Three systems of insular functional connectivity identified with cluster analysis. Cereb Cortex (2011) 21:1498-506. doi:10.1093/cercor/bhq186

29. Stephani C, Fernandez-Baca G, Maciunas R, Koubeissi M, Lüders H. Functional neuroanatomy of the insular lobe. Brain Struct Funct (2011) 216:137-49. doi:10.1007/s00429-010-0296-3

30. Quartarone A, Rizzo V, Morgante F. Clinical features of dystonia: a pathophysiological revisitation. Curr Opin Neurol (2008) 21:484-90. doi:10.1097/WCO. 0b013e328307bf07

31. Purves D, Augustine GJ, Fitzpatrick D, Katz LC, LaMantia AS, McNamara JO, et al. Neuroscience. 2nd ed. Sunderland, MA: Sinauer Associates (2001).

32. Smith SM, Fox PT, Miller KL, Glahn DC, Fox PM, Mackay CE, et al. Correspondence of the brain's functional architecture during activation and rest. Proc Natl Acad Sci U S A (2009) 106:13040-5. doi:10.1073/pnas. 0905267106
33. Delnooz CC, Pasman JW, Beckmann CF, van de Warrenburg BP. Task-free functional MRI in cervical dystonia reveals multi-network changes that partially normalize with botulinum toxin. PLoS One (2013) 8(5):e62877. doi:10.1371/ journal.pone.0062877

34. Sack AT. Parietal cortex and spatial cognition. Behav Brain Res (2009) 202:153-61. doi:10.1016/j.bbr.2009.03.012

35. Cavanna AE, Trimble MR. The precuneus: a review of its functional anatomy and behavioural correlates. Brain (2006) 129:564-83. doi:10.1093/brain/awl004

36. Hinse P, Leplow B, Humbert T, Lamparter U, Junge A, Emskötter T. Impairment of visuospatial function in idiopathic spasmodic torticollis. J Neurol (1996) 243:29-33. doi:10.1007/BF00878528

37. Wenzel T, Schnider P, Wimmer A, Steinhoff N, Moraru E, Auff E. Psychiatric comorbidity in patients with spasmodic torticollis. J Psychosom Res (1998) 44:687-90. doi:10.1016/S0022-3999(97)00229-8

38. Lencer R, Steinlechner S, Stahlberg J, Rehling H, Orth M, Baeumer T, et al. Primary focal dystonia: evidence for distinct neuropsychiatric and personality profiles. J Neurol Neurosurg Psychiatry (2009) 80:1176-9. doi:10.1136/jnnp.2008. 170191

39. Fabbrini G, Berardelli I, Moretti G, Pasquini M, Bloise M, Colosimo C, et al. Psychiatric disorders in adult-onset focal dystonia: a case-control study. Mov Disord (2010) 25:459-65. doi:10.1002/mds.22983

40. Neychev VK, Gross R, Lehéricy S, Hess E, Jinnah HA. The functional neuroanatomy of dystonia. Neurobiol Dis (2011) 42:185-201. doi:10.1016/j.nbd. 2011.01.026

41. LeDoux MS, Brady KA. Secondary cervical dystonia associated with structural lesions of the central nervous system. Mov Disord (2003) 18:60-9. doi:10.1002/mds.10301

42. Scott BL, Jankovic J. Delayed-onset progressive movement disorders after static brain lesions. Neurology (1996) 46:68-74. doi:10.1212/WNL.46.1.68

43. Terribilli D, Schaufelberger M, Duran F, Zanetti M, Curiati P, Menezes P, et al. Age-related gray matter volume changes in the brain during non-elderly adulthood. Neurobiol Aging (2011) 32:354-68. doi:10.1016/j.neurobiolaging.2009. 02.008

44. Delnooz CC, Pasman JW, van de Warrenburg BP. Dynamic cortical gray matter volume changes after botulinum toxin in cervical dystonia. Neurobiol Dis (2015) 73:327-33. doi:10.1016/j.nbd.2014.10.013

45. Haslinger B, Altenmüller E, Castrop F, Zimmer C, Dresel C. Sensorimotor overactivity as a pathophysiologic trait of embouchure dystonia. Neurology (2010) 74:1790-7. doi:10.1212/WNL.0b013e3181e0f784

46. Houdayer E, Beck S, Karabanov A, Poston B, Hallett M. The differential modulation of the ventral premotor-motor interaction during movement initiation is deficient in patients with focal hand dystonia. Eur J Neurosci (2012) 35:478-85. doi:10.1111/j.1460-9568.2011.07960.x

47. Moll CK, Galindo-Leon E, Sharott A, Gulberti A, Buhmann C, Koeppen JA, et al. Asymmetric pallidal neuronal activity in patients with cervical dystonia. Front Syst Neurosci (2014) 8:15. doi:10.3389/fnsys.2014.00015

Conflict of Interest Statement: None of the authors have conflicts of interest directly related to the development of the manuscript. Full financial disclosures can be found in the Acknowledgments section.

Received: 04 October 2014; accepted: 14 December 2014; published online: 08 January 2015.

Citation: Piccinin CC, Piovesana LG, Santos MCA, Guimarães RP, De Campos BM, Rezende TJR, Campos LS, Torres FR, Amato-Filho AC, França MC Jr, Lopes-Cendes I, Cendes F and D'Abreu A (2015) Diffuse decreased gray matter in patients with idiopathic craniocervical dystonia: a voxel-based morphometry study. Front. Neurol. 5:283. doi: 10.3389/fneur.2014.00283

This article was submitted to Movement Disorders, a section of the journal Frontiers in Neurology.

Copyright (C) 2015 Piccinin, Piovesana, Santos, Guimarães, De Campos, Rezende, Campos, Torres, Amato-Filho, França, Lopes-Cendes, Cendes and D'Abreu. This is an open-access article distributed under the terms of the Creative Commons Attribution License (CC BY). The use, distribution or reproduction in other forums is permitted, provided the original author(s) or licensor are credited and that the original publication in this journal is cited, in accordance with accepted academic practice. No use, distribution or reproduction is permitted which does not comply with these terms. 